\title{
Designing of a dietary regimen and lifestyle guidelines for people who are prone to gastro esophageal reflux disease
}

\author{
T. Usai, T. Mushawarima, C. Zvidzai \\ Department of Food Science and Nutrition, P Bag 9055, Gweru, Zimbabwe \\ (Chinhoyi University of Technology P. Bag 7724, Chinhoyi, Zimbabwe \\ (United Bulawayo Hospitals P.O. Box 958 Bulawayo, Zimbabwe
}

\begin{abstract}
People with gastroesophageal reflux disease (GERD) may experience relief of symptoms upon taking low carbohydrate, fruits, low protein and low fat diet in appropriate quantities. This study focuses on assessing the effect of a prescribed diet in relieving GERD symptoms on patients experiencing the problem. Questionnaires were used to gather information on diet and GERD symptoms of the participants. Helicobacter pylori analysis andbody mass index (BMI) of the participants were determined. The results show that the prescribed diet resulted in reduced weight and disappearance of most GERD symptoms. The results have shown the potential of the diet in eliminating GERD symptoms.
\end{abstract}

Keywords: - diet, GERD, heartburn, low carbohydrate, symptoms

\section{INTRODUCTION}

Several diet recommendations for people who are prone to heartburn or GERD are available. Heartburn is the backward flow or regurgitation of stomach contents passing up into the esophagus [1]. Heartburn begins as a burning pain in the middle of the chest, behind the breast bone, often after a big meal. Since different foods contain many different nutrients, it is important to select food wisely, plan diets properly and come up with methods of preparing foods for maximum absorption. Heartburn has become a problem in Zimbabwe as many people are complaining of it. Consumption of fast foods is on the increase in Zimbabwe (personal observation) perhaps because more and more women are joining the working class and prefer fast and convenient foods that save them from the labour of selecting, planning and preparing of family meals.

Apart from diet, heartburn can also be caused by some medical drugs such as ARV tablets like stuvudine, which is administered in combination with lamuvudine and nevirapine [2]. Some medications such as bisphosphalates, iron salts, potassium salts, and certain pain medication and antibiotics potentially make people more susceptible to heartburn [1].

Burgess [3], Vakil [4] and Alvarenga et al [5] revealed that obesity ranks high on the list of contributing causes of heartburn because the adipose tissue in the abdomen crowds the stomach, so that food does not settle down totally into the stomach area. Several recent cross-sectional studies have demonstrated a positive association between heartburn and high body mass index (BMI). The physiopathology for the association of heartburn and BMI can be explained by inappropriate lower esophageal sphincter relaxation arising from hiatal hernia or increase in intra-abdominal pressure, both leading to increase in acid reflux [6].

Serious heartburn if not taken care of could cause burning chest pains, blotted full stomach, experience of early satiety, an acid or bitter taste at the back of the throat, bad breath, an increase in pain severity when lying down or bending over, headache, nausea, vomiting, weakness of the body and could develop into ulcers of the esophagus and cancer [3].

Hopewood [7] recommended intake of foods such as avocados, bananas, grapes, honey, lemons, maple fruit, millet, mellows, molasses, oranges, raisins, white meat and all types of vegetables. These foods are alkaline forming foods that neutralize body acids thereby reducing changes for the development of heartburn. Phosphorus and sulphur act as buffers to maintain $\mathrm{pH}$ so it is highly recommended to eat $50 \%$ of raw fresh fruits and vegetables especially cabbage.

Lifestyle interventions have been reported in literature as one way of reducing GERD. Avoiding chocolate, alcohol, coffee and tobacco is recommended for GERD treatment [8]. Medications such as antacids [9], Histamine H2-receptor [10] antagonists (ranitidine, famotidine, cimetidine, nizatidine) and proton pump inhibitors (PPI) such as pantoprazole, lansoprazole, esomeprazole, omeprazole and rabeprazole [11]. Antacids and histamine H2-receptor antagonists provide temporary relief. The use of these medicines for treatment induces body tolerances within two weeks. PPIs are more effective for the treatment of GERD than antacids. Surgical interventions were cited as another way of treating GERD [12]. Low carbohydrate has been reported [13-15] as alternatives to GERD treatment. 
Heartburn is now a common problem in Zimbabwe to the best of our knowledge no published research has been done on the awareness and availability of recommended foods for heartburn sufferers in Zimbabwe. This study will therefore be a first step in addressing this problem through generating information that will be used in designing a suitable diet for heartburn sufferers. People would be able to select foods that prevent heartburn and those which aid digestion of foods and also to change their life styles by using suitable methods of food preparation.

\subsection{Population and sampling}

\section{METHOD}

In this study the researcher selected 5 participants from United Bulawayo Hospital workers using convenient sampling. A questionnaire was used to gather information on diet from the participants. The reflux core test index was used to determine the severity of heartburn among participants. The participants were on strict diet with appropriate amounts. The breakfast diet was selected from the following foods namely maize/millet porridge, cereal, 1 slice of bread, teaspoon margarine or peanut butter, roibos tea with milk, 1 egg, cheese slice for breakfast. Lunch was selected from sandwiches, cucumber, sausage rolls, rice, lemon tea, boiled potatoes, chicken, macaroni, baked chips, fruit juice, mixed green salads, fruits and tuna fish. Respondents were supposed to take pistachio nuts, biscuits, fruits, popcorn as snacks. Dinner was selected from rice, maize meal (sadza), pasta, chicken, fish, beef, cabbage, green vegetables, beetroot, broccoli and fruits. BMI and Helicobacter pylori analysis was administered on the participants.

\subsection{Body Mass Index (BMI)}

The BMI assessment was done to see if the weight of heartburn sufferers is the contributing factor to heartburn problems. A cohort method of analysis was used that would show the difference on those on the dietary intervention and those who were not, this was done before, during and after the intervention (the designing of the dietary regimen). The body mass index was calculated before, during and after the intervention. The BMI is important for heartburn sufferers so that they keep a healthy weight, because overweight increases pressure in the stomach and causes esophageal reflux which will cause heartburn hence the need to exercise and to reduce the amount of starchy foods which in turn will be stored as adipose tissue.

\subsection{Helicobacter pylori analysis}

Microbiological analysis was done for Helicobacter pylori. Bacterial growth for example overgrowth of Helicobacter pylori is particularly dangerous, most of the fiber consumed escape digestion and become intestinal food for bacteria. H. pylori produce toxins that damage the mucosal lining of the esophagus causing heartburn and may cause ulcers or develop to cancer, hence the need to design a diet which reduce microbial load which include ginger, mastic-a resin from a Mediterranean and Middle Eastern variety of Pistachio tree [16].

\subsection{BMI}

\section{RESULTS}

Table 1 shows BMI data of respondents before and after a 2 week strict diet and exercise. The weight of all the respondents decreased after taking the diet and scheduled exercises resulting in a lowered BMI. A low carbohydrate diet resulted in burning of some of the stored fats. Decreased amounts of protein intake to the required level also contributed to a decrease in weight.

Table 1: BMI of respondents before and after diet

\begin{tabular}{|l|l|l|l|l|l|}
\hline Respondents & A & B & C & D & E \\
\hline Height $(\mathrm{m})$ & 1.65 & 1.65 & 1.7 & 1.65 & 1.65 \\
\hline Weight before diet $(\mathrm{kg})$ & 63 & 78.9 & 103 & 79 & 106 \\
\hline Weight after diet $(\mathrm{kg})$ & 61 & 70.7 & 90 & 75 & 95 \\
\hline BMI before $\left(\mathrm{kgm}^{-2}\right)$ & 24 & 29 & 36 & 33 & 40 \\
\hline BMI after( $\left(\mathrm{kgm}^{-2}\right)$ & 23 & 26 & 31 & 30 & 35 \\
\hline
\end{tabular}

\subsection{The reflux symptom score index}

Table 2 shows the effect of the diet on GERD symptoms. Reflux symptom index scale rates the symptoms on a scale of 1-5. A score of 5 shows a severe problem while a score of 0 shows no problem. All the respondents did not have a hoarse voice which is associated with erosion of the esophagus. All the respondents had problems with clearing of throat which disappeared after taking the diet. Excess throat mucus disappeared after taking the diet except for respondent E. Symptoms such as difficult in swallowing food, annoying cough and coughing after eating completely disappeared for all patients after taking the diet. All except for respondent 
E experienced complete clearance of symptoms of breathing difficulties, sensations of something sticking in throat and chest pains. This could be explaining by the fact that participant $\mathrm{E}$ was very obese. Respondents $\mathrm{C}$ and D show slight problems with clearing throat (score 1) after taking the diet. The other respondents had completely clear throat after taking the diet.

Table 2: GERD symptoms before and after diet

\begin{tabular}{|c|c|c|c|c|c|c|c|c|c|c|}
\hline \multirow[t]{3}{*}{ Symptoms } & \multicolumn{10}{|c|}{ Strict diet score } \\
\hline & \multicolumn{5}{|c|}{ Before } & \multicolumn{5}{|c|}{ After } \\
\hline & $\mathrm{A}$ & $\mathrm{B}$ & $\mathrm{C}$ & $\mathrm{D}$ & $\mathrm{E}$ & $\mathrm{A}$ & $\mathrm{B}$ & $\mathrm{C}$ & $\mathrm{D}$ & $\mathrm{E}$ \\
\hline Hoarseness or a problem with your voice & 0 & 0 & 0 & 0 & 0 & 0 & 0 & 0 & 0 & 0 \\
\hline Clearing your throat & 2 & 4 & 3 & 3 & 4 & 0 & 0 & 1 & 1 & 0 \\
\hline Excess throat mucus or postnatal drip & 0 & 5 & 4 & 1 & 3 & 0 & 0 & 0 & 0 & 3 \\
\hline Difficulty swallowing food, liquids or pills & 3 & 4 & 4 & 3 & 0 & 0 & 0 & 0 & 0 & 0 \\
\hline Coughing after you ate or lie down & 1 & 1 & 1 & 3 & 0 & 0 & 0 & 0 & 0 & 0 \\
\hline Breathing difficulties or choking episodes & 2 & 2 & 2 & 3 & 3 & 0 & 0 & 0 & 0 & 2 \\
\hline Troublesome or annoying cough & 0 & 2 & 4 & 1 & 1 & 0 & 0 & 0 & 0 & 0 \\
\hline $\begin{array}{l}\text { Sensations of something sticking in your throat } \mathrm{A} \\
\text { lump in your throat }\end{array}$ & 3 & 3 & 0 & 3 & 4 & 0 & 0 & 0 & 0 & 4 \\
\hline $\begin{array}{l}\text { Heart, chest pain, indigestion, or stomach acid coming } \\
\text { up }\end{array}$ & 4 & 4 & 4 & 4 & 5 & 0 & 0 & 0 & 0 & 4 \\
\hline
\end{tabular}

Fig. 1 show that the composite scores for the symptoms. The composite of these scores should be 10 or below. If it is more than 10, you should consider an evaluation to check for GERD. All the participants had a score above 10. However after taking the diet all except $\mathrm{E}$ had scores below 10. This could be explained by fact that the participant $\mathrm{E}$ was very obese.

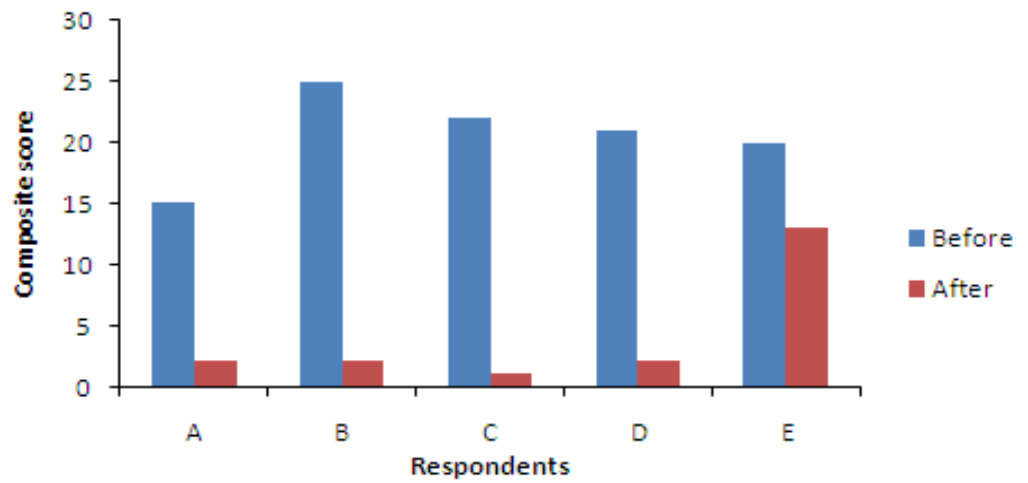

Fig 1: Composite reflux score for GERD

\subsection{Responses to prescribed diet}

Table 3 shows the list of foods which cause heartburn to the respondents before taking the prescribed diet. The foods that were cited by respondents are in agreement with the foods that were previously reported by Berardi [1]. The main symptoms that were induced by these foods include heart and chest pain, indigestion and stomach acid coming up.

Table 3: Food causing GERD symptoms before diet

\begin{tabular}{|l|l|l|l|l|l|}
\hline Respondent & A & B & C & D & E \\
\hline $\begin{array}{l}\text { Food causing } \\
\text { heart burn }\end{array}$ & $\begin{array}{l}\text { Chocolate, coffee, } \\
\text { sugar beans }\end{array}$ & $\begin{array}{l}\text { Mayonnaise, } \\
\text { peanut butter }\end{array}$ & $\begin{array}{l}\text { Alcoholic } \\
\text { beverages }\end{array}$ & $\begin{array}{l}\text { Dried vegetables, } \\
\text { spicy foods }\end{array}$ & $\begin{array}{l}\text { Sweet potatoes, } \\
\text { round nuts }\end{array}$ \\
\hline
\end{tabular}

Table 4 shows some of the prescribed foods that caused GERD symptoms from the prescribed diet. The respondents were advised to withdraw from foods that aggravate GERD symptoms. Some of them experienced the symptoms after taking large amounts of the prescribed foods during breakfast, lunch or supper.

Table 4: Food causing GERD symptoms after taking diet

\begin{tabular}{|l|l|l|l|l|l|}
\hline Respondent & A & B & C & D & E \\
\hline $\begin{array}{l}\text { Food causing heart } \\
\text { burn }\end{array}$ & $\begin{array}{l}\text { buns, baked } \\
\text { beans }\end{array}$ & $\begin{array}{l}\text { Pumpkin pudding, } \\
\text { sweet potato }\end{array}$ & $\begin{array}{l}\text { Maize porridge, } \\
\text { dried vegetables }\end{array}$ & Sour milk & Spicy beef \\
\hline
\end{tabular}

\subsection{Helicobacter pylori}


All the five respondents showed a positive result to $H$. pylori tests before administering the diet. However all the respondents show a negative test after having the diet for two weeks. All the correspondents were taking pistachio nuts that are responsible for destroying bacteria in the stomach. Helicobacter pylori are the bacteria responsible for causing digestive illnesses including gastritis and peptic ulcer disease. Heidal [16], suggested using mastic (a resin from a Mediterranean and Middle Eastern variety of pistachio tree to treat $H$. pylori. Pistachios are a rich source of essential nutrients, fiber and protein, low in saturated fat and cholesterol free.

\section{CONCLUSION}

The five respondents described in this study experienced relief of GERD symptoms after taking the prescribed diet in appropriate amounts. Their observations suggest that reducing fats, carbohydrates and proteins contributed to symptom relief. However, this conclusion is confounded by concurrent reduction of caffeine, alcoholic beverages, fatty, spicy and sweet foods. The diet contained lots of fruits and vegetables ensuring that the responds were filled up most of the times. Fruits also provided vitamins and fibers that help in food digestion. Drinking lots of water also made the digestion and absorption of food easy. These conclusions are however preliminary and further studies need to be carried out to find out whether including daily exercises will improve the BMI of respondents over a long period.

\section{REFERENCES}

[1]. R.R. Berardi, Self directed options for preventing or treating heartburn, Pharmacy review, United States of America, 2006.

[2]. H. Silverman, Food Nutrition Health, Britain, Symour Press Ltd, 1992.

[3]. J. Burgess, Stop the pain in 30 days Naturally, No More Heartburn, Kensington Publishers, 2007-2008, 63:95-96.

[4]. N. Vakil 2010, Best Practise and research clinical gastroenterology, disease definition, clinical manifestation, Epidemiology and Natural History of GERD, 24, 2010, 759-764.

[5]. J.C.L. Alvarenga, J. Vargas L.H. Lopez, R. Fass, S. Sobrino-cossio and A. Comuzzie, Archives of medical research, effect of body weight and esophageal damage on the severity of gastroesophageal reflux symptoms, Mexican GERD Working Group, 40, 2009, 576-581.

[6]. H. Hampel, N.S. Abraham and H.B. El-Serag, Meta-analysis: obesity and the risk for gastroesophageal reflux disease and its complications, Ann Internal Medicine, 2005, 143, 199-211.

[7]. S. Hopewood, S. Advanced Food Science, USA, Macmillan Publishing Company, 1996.

[8]. T. Kaltenbach, S. Crockett and L.B. Gerson, Are lifestyle measures effective in patients with gastroesophageal reflux disease? An evidence-based approach, Arch Internal Medicine, 2006; 166, 965-971.

[9]. M. Pettit, Treatment of gastroesophageal reflux disease, Pharmacy World and Science, 2005, 27, 432435 .

[10]. M. Khan, J. Santana and N. Donnellan, Medical treatments in the short term management of reflux oesophagitis. Cochrane Database of Systematic Reveiws, 2007, 2, CD003244.

[11]. N.J. Shaheen, R.A. Hansen and D.R. Morgan, The burden of gastrointestinal and liver diseases, The American Journal of Gastroenterology, 2006, 101, 2128-2138.

[12]. S. Ip, P. Bonis, A. Tatsioni, G. Raman and P. Chew, Comparative effectiveness of management strategies for gastroesophageal reflux disease. Comparative Effectiveness Reviews, No 1. Rockville, MD: Agency for Healthcare Research and Quality. December 2005. www.ncbi.nlm.nih.gov/ books/NBK42949/.

[13]. W.S. Yancy, D. Provenzale and E.C. Westman, Improvement of gastroesophageal reflux disease after initiation of a low-carbohydrate diet: five brief case reports, Alternatives Therapies in Health and Medicine, 2001, 7(120), 116-119.

[14]. Yudkin J, Evans E, Smith MG. The low-carbohydrate diet in the treatment of chronic dyspepsia, Proceedings of the Nutrition, Society, 1972, 31, 12A.

[15]. G.L. Austin, M.T. Thiny and E.C. Westman, A very low-carbohydrate diet improves

[16]. gastroesophageal reflux and its symptoms, Digestive Diseases and Science 2006, 51, 1307-1312.

[17]. K. Heidal, N. Lewis and S. Evans, Survey of omega-3 fatty acid intakes and omega-3 food selections in cardiac patients living in a section of the Midwestern United States, Nutrition Research, 24(9), 2004, 741-747. 